\title{
The Glowing Screen Before Me and the Moral Law Within me: A Kantian Duty Against Screen Overexposure
}

\author{
Stefano Lo $\operatorname{Re}^{1,2}$ (D)
}

Accepted: 7 November 2021 / Published online: 20 December 2021

(c) The Author(s) 2021

\begin{abstract}
This paper establishes a Kantian duty against screen overexposure. After defining screen exposure, I adopt a Kantian approach to its morality on the ground that Kant's notion of duties to oneself easily captures wrongdoing in absence of harm or wrong to others. Then, I draw specifically on Kant's 'duties to oneself as an animal being' to introduce a duty of self-government. This duty is based on the negative causal impact of the activities it regulates on a human being's mental and physical powers, and, ultimately, on the moral employment of these powers. After doing so, I argue that the duty against screen overexposure is an instance of the duty of selfgovernment. Finally, I consider some objections.
\end{abstract}

Keywords Kant $\cdot$ Duties to oneself $\cdot$ Screen addiction $\cdot$ Internet addiction

\section{Introduction}

This paper introduces a Kantian duty against immoderate engagement with screen-based technologies (screen overexposure). In the first section, after providing a family resemblance definition of screen exposure, I advocate adopting a Kantian approach to its morality. In particular, Kant's notion of duties to oneself can capture wrongdoing in absence of harm or wrong to others as essentially a lack of self-respect, which affords us a richer moral picture. In the second section, I draw specifically on the chapter on 'duties to oneself as an animal being' in Kant's Doctrine of Virtue to develop a duty of self-government. This duty is based on the negative causal impact of certain activities on the human being's mental and physical powers, and ultimately on the moral employment of these powers. Introducing it lets us avoid problematic teleological interpretations of Kant's arguments against

Stefano Lo Re

stelore87@gmail.com

1 Centre for Ethics, Philosophy, and Public Affairs, University of St Andrews, St Andrews, UK

2 Academia Kantiana, Institute for the Humanities, Immanuel Kant Baltic Federal University, Kaliningrad, Russia 
the vices of drunkenness, gluttony, and lust. It also provides a single rationale for the duties against all three, which is elegant. Moreover, this rationale can serve as a basis to establish new duties-importantly for my purpose, the duty against screen overexposure. After some methodological remarks on the empirical component of the negative causal impact argument, in the third section I sketch the contours of Kantian self-government. A notable upshot of this account is the permissibility of occasional overindulgence. In the last section, I consider objections concerning the extensional adequacy of my account, its Kantian credentials, the introduction of the duty against screen overexposure, and the independent support for adopting a Kantian approach.

\section{Screen Overexposure and Moral Philosophy}

\section{Screen Exposure}

In recent years, there has been a renewed scientific interest in the adverse effects of the use of technology. The research has focused in particular on the medical and psychological repercussions of activities involving new screen-based technological devices, often with a special attention given to their impact on children and young people. The terms employed in this field are still being established, and so there is little terminological uniformity. ${ }^{1}$ This research is complemented by public discussions on whether such technologies are harmful to the individual or to society at large. In fact, public opinion likely anticipated the worries that then became subject of scientific investigation.

In this paper, I use screen exposure as an umbrella term for screen-based activities potentially raising worries of this kind. This term is meant to include a wide range of activities (e.g. browsing social media, watching series, playing video games) involving various technological devices (e.g. smartphones, computers, virtual reality sets). I group these activities on a family resemblance basis, although exposure to a screen strikes me as their most common feature, so that it may be

\footnotetext{
1 The following examples suffice as evidence of the scientific interest in the topic, and of the relative consensus that at least certain instances of what I call 'screen exposure' are harmful (see also the beginning of the next subsection). The vocabulary of addiction has been used in relation to electronic screens (Kardaras 2014), the internet (Kuss et al. 2014), and smartphones (Yildiz 2017). A disorder named 'electronic screen syndrome' has been introduced (Dunckley 2017). The impact of 'screen time' on wellbeing has been assessed (Twenge, Martin, and Campbell 2018). Diagnosis tests for Facebook (Andreassen et al. 2012), smartphones (Kwon et al. 2013), and internet addiction (Young 2016) have been put forward, and the latter's association to symptoms of various psychiatric conditions (e.g. ADHD and depression) has been investigated (Ko et al. 2012). There is debate over the possible harmful effects of digital pornography (see n. 20 below). The WHO has recently recognised the 'gaming disorder' (World Health Organization 2018; see Pontes et al. 2019), and the APA has deemed it worthy of further study (American Psychiatric Association 2013; see Petry et al. 2015). However, note that the DSM includes none of the conditions mentioned here; and that the inclusion of 'non-substance addictions' is itself controversial (Potenza 2014).
} 
thought of as a necessary - although by no means sufficient - condition for 'screen exposure'. ${ }^{2}$ Although the discussion of screen exposure would benefit from further analysis, this family resemblance approach is sufficient for my purpose, and adequate to the evolving nature of the phenomenon and to its relative novelty as an object of philosophical attention.

\section{Screen Overexposure and Moral Philosophy}

There is some consensus in the scientific community and in public opinion that screen overexposure is harmful (see n. 1). This harm is thought to extend beyond the mere bodily consequences of protracted looking at screens, and rather to include cognitive, psychological, and social dimensions. All these provide harm-based reasons against screen overexposure. However, while relevant, such reasons are not everything that moral philosophy has to offer. A different, if compatible perspective is provided by the philosophy of Immanuel Kant, which affords us a richer picture of what is wrong with screen overexposure.

This may sound surprising: Kant's moral philosophy is often thought to be so abstract and insensitive to the complexities of real life to be unsuitable to tackle new, contemporary problems. However, in recent years this image of Kant, mainly based on what in fact are his foundational moral works (e.g. the 1785 Groundwork of the Metaphysics of Morals), has started to change. This is due to a growing body of literature on his Doctrine of Virtue (1797), which, arguably, contains his normative ethics. Many elements of this work defy the image traditionally associated with Kant, from the role of human ends and feelings, to discussions of various kinds of social interaction, to the presence of more or less open-ended casuistical questions (Trampota et al. 2013, pp. 1-2). ${ }^{3}$

\section{Kantian Preliminaries}

In the next sections, I argue for a Kantian duty against screen overexposure as an instance of a more general duty of self-government. Before doing so, I should highlight the two main features of Kant's theory that make it an appealing option in the context of this project. The first is its distinction between prudence and morality (GMS 4:414-9; KpV 5:34-9). The former is a conditional kind of normativity

\footnotetext{
${ }^{2}$ A feature which, however, is not morally salient (see the section 'Why a duty against screen overexposure? And why a Kantian duty of self-governance?' below). Note that some non-screen-based activities (e.g. drinking) raise similar concerns to those raised by screen exposure, and some screen-based technologies are unlikely to do so (e.g. electronic readers).

3 Besides Trampota, Sensen, and Timmermann (2013), see Timmons (2002), Betzler (2008); and Denis (2010), and particularly, Hill (2010). On the relation between Kant's foundational works and mature system, see Timmermann (2007, pp. 169-171) and Wood (2002). Recent Kant-inspired contributions in applied ethics address topics such as organ donation (Alpinar-Şencan 2016), and suicide and euthanasia (Cholbi 2015). For recent discussions of casuistry and casuistical questions, see Schüssler (2012); Schumski (2017).
} 
concerned with the attainment of happiness. As such, it can only recommend courses of action, and do so on account of the end to be attained. Morality is the sphere of unconditional commands. As rational beings, we are required to adopt principles that conform to the only law that could govern a good will, the Categorical Imperative (GMS 4:421). This is a purely formal law binding solely in virtue of being freely self-legislated, without reference to any antecedent end. It is on account of this autonomy that human beings have the special dignity of ends in themselves (GMS 4:434).

The distinction between prudence and morality makes room for moral considerations beyond those based on harm. A second, less known element of Kant's philosophy plays an even more important role in my discussion. It is the idea of duties to oneself (TL 6:417-447). Kantians distinguish duties to oneself in a thin and a thick sense (Timmermann 2013; Atwell 1986, pp. 128-129). The thin, or comprehensive sense captures the idea that all moral duties are also duties to oneself insofar as the possibility of any obligation rests on the self-binding nature of the human will (TL $6: 417-420) .{ }^{4}$ The basis of my account of a duty against screen overexposure will be the thick, or contrastive sense of duties to oneself-duties which are owed to oneself as opposed to being owed to others. This notion is interesting in the present context because it makes room for the impermissibility of certain actions and attitudes in absence of harm or wrong to others. Indeed, harm and wrong to others are relevant to the Kantian moral picture of self-regarding acts. In focusing on duties to oneself, however, I choose to draw on what is distinctive about the Kantian framework.

\section{Duties to Oneself and Kantian Duties to Oneself}

Duties to oneself arguably are embedded in our pre-theoretical, everyday conception of morality (Timmermann 2006a, p. 505 and p. 526). Not only does the latter include expressions pointing to them (e.g. 'self-respect', or 'owing it to oneself'); the wrongness of certain actions or attitudes seems hard to account for without appealing to them (e.g. servile behaviour; Timmermann 2006a, 527). Intuitively, the wrongness of such actions or attitudes need not involve a prudential failure concerning one's own best interest; and the basis for the reproach incurred cannot be reduced to the harm or wrong to others. ${ }^{5}$

\footnotetext{
4 The thin sense of duties to oneself is all the more controversial if it is seen as necessarily resting on contentious metaphysical claims, notably Kant's distinction between 'homo noumenon' and 'homo phaenomenon', that is, between the human being 'as a natural being that has reason' and 'as a being endowed with inner freedom' (TL 6:418; see Byrd and Hruschka 2010, Ch. 14). It is by means of this distinction that Kant claims to solve the seeming paradox of self-obligation, but it is not exactly clear how this is supposed to work. For example, on Jens Timmermann's reconstruction, homo noumenon's obligating homo phaenomenon also results in an obligation on homo noumenon, which is problematic (Timmermann 2013, p. 217; Samuel Kerstein's reading is vitiated by a mistaken textual conjecture: compare Kerstein 2008, pp. 205-206 with Timmermann 2013, p. 217 n. 26). However, less metaphysically loaded Kant-inspired accounts of self-obligation are also available, for example those inspired by Stephen Darwall's work on the 'second-personal standpoint' (Darwall 2006, 2012; see Schaab (2021a, b).

5 On servility (TL 6:434-437), see Hill (1973). Timmermann introduces five criteria to identify a clear substantive duty to oneself: '[(i)] that an act or maxim is ... good or bad, (ii) that corresponding rules of conduct go beyond ... prudence, (iii) that such an act or maxim ... is not good or bad because others are
} 
Despite this, the idea of duties to oneself gets a bad rap in the currently predominant philosophical conception of morality. Traditionally thought to be a central element of morality, duties to oneself suffered a serious blow with the publication of Marcus Singer's famous attack on them (1959). After the short-lived debate which immediately followed it, ${ }^{6}$ 'duties to oneself have largely disappeared from the radar of academic philosophers' (Cholbi 2015a, p. 852). This subsection provides some more defense of duties to oneself, particularly of the Kantian conception of duties to oneself.

Within a Kantian framework, violating duties to oneself is essentially a lack of self-respect, a failure to treat oneself in a way that is consistent with one's dignity as a rational, and ultimately as a moral being. This conception of duties to oneself is largely immune to the traditional criticisms raised against them. ${ }^{7}$ The first is Singer's main charge: duties to oneself are incoherent because 'one could release oneself [from them] at will' (Singer 1959, p. 202). This argument, some Kantians respond, begs the question as it simply asserts the non-existence of duties to oneself: if there are duties to oneself, one cannot release oneself from the obligations they impose (Cholbi 2015a, p. 852; Timmermann 2006a, p. 516). ${ }^{8}$ With the same objection in mind, Lara Denis (1997) fleshes out the Kantian conception of moral obligation as a constraint imposed by one's acknowledgment of humanity, in other individuals and in oneself, which makes self-release impossible with regard to duties owed to either. This serves to address a second objection, namely, that duties to oneself have no place in morality because morality is only about other-regarding actions (Baier 1958, cited in Denis 1997). The Kantian account of moral obligation allows us to disambiguate duties to the self from duties regarding the self, and is the basis of a conception of morality that refuses to assign a privileged status to how we treat others (Denis 1997, pp. 333-334; see the subsection 'Why a duty against screen overexposure? And why a Kantian duty

\footnotetext{
Footnote 5 (continued)

affected, and (iv) that it is generally and plausibly classed among things moral. Moreover, any such duty must (v) not give the appearance that it has been invented merely to counterbalance the rigour of duties to others' (2006a, p. 527). Unlike the duty to oneself merely as moral being, which is violated by servile behaviour, duties to oneself regarded as moral and natural being, the basis of my account, do not seem to satisfy (ii). This is not surprising, but it does not mean that the duties reduce to prudential recommendations. The resulting rules of conduct overlap, and compliance with them may well be motivationally overdetermined. However, the duties are not grounded in prudential considerations, and should not be confused with them.

6 Kading (1960), Wick (1960, 1961), Mothersill (1961), Knight (1961), and Singer (1963).

7 I should thank an anonymous reviewer at Res Publica for inviting me to provide more context on the status of duties to oneself, particularly of Kantian duties to oneself, in the literature. My review of objections is indebted to Timmermann (2006a) and especially Denis (1997). Both discuss further objections.

8 Recent defenses of duties to oneself focus primarily on Singer's claim about self-release. For example, Daniel Muñoz (2020) argues that while it is possible to release oneself from an obligation, one is under that obligation until one effectively does so. In a similar vein, Janis Schaab (2021b) rejects the assumption, implicit in Singer's argument, that the possibility to release oneself from an obligation entails the impossibility of violating that obligation.
} 
of self-governance?' below). A third, related objection is that duties to oneself are just claims of self-interest in disguise (Williams 1985). This simply cannot be true of Kantian duties to oneself, since the constraints they impose are not limited to cases of imprudence (Denis 1997, p. 333). A final objection is that duties to oneself imply state paternalism. Here, Kant's distinction between legal and ethical obligation (MS 6:218-221) allows him to separate the question concerning the reach of state legislation from that concerning whether an action is bad (Timmermann 2006a, p. 521).

\section{Kantian Resources}

\section{A Duty of Self-Government}

The main element on which I draw in developing a Kantian duty against screen overexposure is the chapter of the Doctrine of Virtue on the perfect duty to oneself as an animal being (TL 6:421-428). ${ }^{9}$ Immediately before it, in the general introduction to duties to oneself, Kant puts forward two criteria for the classification of thick duties to oneself. The first establishes the traditional Kantian distinction between perfect duties, which are negative and prohibit actions, and imperfect duties, which are positive and command the adoption of ends. Kant describes the duties to oneself belonging to each category as having to do respectively with the 'moral health (ad esse)' and the 'moral prosperity (ad melius esse[)]' of the human being (TL 6:419). The second criterion is whether the human being is considered 'both as an animal (natural) being and a moral being or only as a moral being' (TL 6:420).

In discussing the perfect duty to oneself as (for brevity's sake) an animal being, Kant focuses on the corresponding vices, since the duty is negative (i.e. of omission). Although, strictly speaking, the duty is 'to preserve [oneself] in [one's] animal nature' (TL 6:421), we may speak of a plurality of duties opposed to the vices. ${ }^{10}$ The contrary of the duty, Kant writes, is:

\footnotetext{
${ }^{9}$ In doing so, I rely extensively on Mark Timmons's reading of it (2013), as I find it particularly suitable as a basis for a Kantian duty against screen overexposure. However, such a reading is not uncontroversial, and other options are available on, for example, Kant's account of human nature and of sexuality (see Cohen 2006; 2008b; Frierson 2013; Louden 2011; Varden 2020). I cannot explore the connections between the perfect duty to oneself as an animal being and other relevant elements in Kant's theory: for example, the Groundwork's duty to develop one's talents (GMS 4:422-423; 4:430), which the Doctrine of Virtue subsumes under the obligatory end of one's own perfection; or the indirect duty 'to secure one's own happiness' (GMS 4:399, emphasis added). The claims that moderation in eating or drinking preserves the capacity to enjoy foods and drinks (which Kant makes) and that moderation in sexual activity preserves the capacity to enjoy sexual activity (which he does not) could come together in an argument for acting so as to preserve one's capacity to enjoy life, falling under the indirect duty to secure one's own happiness (see the next subsection, and also n. 28 below).

${ }^{10}$ Kant employs the same 'negative' strategy when discussing the duty to oneself merely as moral being (TL 6:428-436). See Bacin (2013, p. 245).
} 
willful physical death ... which can be thought as either total, suicide (suicidium), or only partial, mutilating oneself. Mutilating oneself can in turn be either material, depriving oneself of certain integral, organic parts, that is, maiming oneself, or formal, depriving oneself (permanently or temporarily) of one's capacity for the natural (and so indirectly for the moral) use of one's powers. (TL 6:421)

In the remainder of the paper, I set aside Kant's discussion of suicide and self-maiming in the first of the three articles of the chapter, and focus on his account of what, on the basis of this classification, should be called 'formal self-mutilation'. This is developed through the second and the third article: 'On defiling oneself by lust' (TL 6:424-426), and 'On stupefying oneself by the excessive use of food and drink' (TL $6: 427-428) .^{11}$

With this restriction in place, the duty to oneself as an animal being can be characterized as a duty to govern oneself so that one's bodily and mental powers can be put to moral use (Timmons 2013, p. 224; Atwell 1986, p. 132; Gregor 1963, p. 144). In the Doctrine of Virtue, the latter amounts not only to respecting other perfect duties, but also to pursuing the obligatory ends of the happiness of others and of one's own perfection (TL 6:382-388; 6:391-394). Indeed, the taxonomy of duties to oneself is completed by the imperfect duties commanding the pursuit of one's own 'natural' and 'moral' perfection (TL 6:444-447). The perfect duty to oneself as an animal being can thus be seen as setting limits on what one may do to oneself qua natural being in view of such positive expansions: the negative duties are 'the first, though not the principal' (TL 6:421, emphases altered). ${ }^{12}$

The alternative to the interpretation above is to read Kant as making a moral argument on the basis of natural teleology. According to this argument, it is impermissible to act contrary to the (alleged) natural purposes of our powers: only the natural-as opposed to 'contra-natural'-use of our powers is permissible. Kant's ambiguity between the two lines of argument persists in the second and third articles of the chapter on the duty to oneself as an animal being. Considering these is necessary to characterize the duty against screen overexposure as an instance of the duty of self-government. ${ }^{13}$

\footnotetext{
${ }^{11}$ Note the contrived parallel in the last indented quote between total and partial physical death on the one hand, and permanent and temporary loss of one's capacities on the other hand. When it comes to formal self-mutilation, Kant distinguishes neither temporary loss and permanent loss of capacities due to one-off actions, nor these from the cumulative adverse effects of certain habits.

${ }^{12}$ Kant says so only with regard to the duty to oneself as animal and moral being, but it is plausible to extend this principle to the duty to oneself only as moral being. Timmons suggests that the principal duty to oneself as animal and moral being is the imperfect, positive one to cultivate one's natural powers (2013, p. 225). If both claims are correct, then the principal duty to oneself as moral being only would be the imperfect, positive one to increase one's moral perfection.

13 This duty is likely related to two other notions: 'moral apathy' (TL 6:408), as the duty not to be governed by feelings and inclinations, and 'autocracy [Autocratie]' (TL 6:383) as moral self-government more generally (but cf. Kant's use at V-Mo/Collins 27:378; see also the end of the subsection 'Lust' below). Developing the connections goes beyond the scope of this paper. See Formosa (2011); Baxley (2010).
} 


\section{Drunkenness and Gluttony}

For ease of exposition, I follow Mark Timmons (2013) in considering the two articles of the chapter in reverse order, beginning with Article III. This pairs together drunkenness and gluttony: ${ }^{14}$

Brutish excess in the use of food and drink is misuse of the means of nourishment that restricts or exhausts our capacity to use them intelligently. Drunkenness and gluttony are the vices that come under this heading. A human being who is drunk is like a mere animal, not to be treated as a human being. When stuffed with food he is in a condition in which he is incapacitated, for a time, for actions that would require him to use his powers with skill and deliberation.--It is obvious that putting oneself in such a state violates a duty to oneself. (TL 6:427)

The beginning of the passage is difficult to read. Charitably, Kant argues that immoderation in eating or drinking affects negatively the capacity to eat or drink sensibly. One problem is that he actually mentions only food ('Nahrung'): Mary Gregor's translation adds 'drink' because both drunkenness and gluttony are listed two lines below. In fact, the beginning of the passage, if we took the original text at face value, would be an odd way to begin a paragraph dedicated to both vices. Moreover, it is plausible to extend Kant's reasoning to drinking. If, as he seems to argue, occasional overeating can be conducive to the establishment of unhealthy eating habits, which excludes eating for nourishment but also taking pleasure in eating, something similar may be said for overdrinking's impact on taste in drinks and social drinking. ${ }^{15}$

Regardless of whether this is a plausible reconstruction of the initial claim in the last indented quotation, I concur with Timmons (2013, p. 235) that the latter's main argument concerns the hindrance of the human being's 'powers' more generally, mentioned immediately before the dash. That quotation is not, however, the only place where Kant is ambiguous about what is negatively affected by indulging in the two vices. Presenting the second criterion for the division of duties to oneself, in the general introduction to duties to oneself, he classifies the duties to oneself as an animal being on the basis of:

\footnotetext{
14 Although it has a more general focus on self-stupefaction, as is clear in the original text ("Von der Selbstbetäubung durch Unmäßigkeit im Gebrauch der Genieß- oder auch Nahrungsmittel'). Kant also mentions 'opium and other vegetable products' (TL 6:427). I follow Mary Gregor's translation, which, however, is not always accurate. I would like to thank Jens Timmermann for drawing my attention to the German text here, and for letting me consult a forthcoming version of Gregor's translation of the Tugendlehre revised by him and Jeanine Grenberg.

15 Kant approaches the latter with indulgence at the end of the article, leaving open whether we can justify 'a use of wine bordering on intoxication, since it enlivens the company's conversation', and to what extent one may permissibly accept invitations at dinner parties, given that they are 'invitations to intemperance' (TL 6:428). On dinner parties as a Kantian reconciliation of our dual nature, see Cohen (2008a). It is unclear whether the last indented passage takes the activities (or their adverse effects) to extend (or cumulate) over time, or whether it considers them in isolation, as one-off instances. See n. 11 above.
} 
impulses of nature having to do with man's animality. Through them nature aims at (a) his self-preservation, (b) the preservation of the species, and (c) the preservation of his capacity to enjoy life, though still on the animal level only.-The vices that are here opposed to his duty to himself are murdering himself, the unnatural use of his sexual inclination, and such excessive consumption of food and drink as weakens his capacity for making purposive use of his powers. (TL 6:420, emphases altered)

Here, drunkenness and gluttony are said to be wrong both because they are contrary to the preservation of the capacity to enjoy life, and because they weaken the human being's bodily and mental powers.

The last two indented passages thus seem to point to different arguments against the vices of drunkenness and gluttony. ${ }^{16}$ One involves the capacity to enjoy life, the other the human being's powers generally. Strictly speaking, both mention the adverse effects of drunkenness and gluttony. However, insofar as the former also appeals to natural teleology (at least in the last indented quotation), I reserve the name negative causal impact argument only for the latter. ${ }^{17}$ Before moving on, I should note that although the question is legitimate, why one ought to preserve one's powers in general, this does not make the latter argument teleological. The only answer Kant can give is that they must be protected in view of their moral employment - an answer which need not refer to natural ends. Any request for further grounds is blocked, as Kant never engages with radical moral skepticism (Timmermann 2007, p. 129; Wood 2007, p. 51 n. 8).

\section{Lust}

The second article of the chapter on duties to oneself as an animal being focuses on lust. I briefly consider it only to set its argument aside, in favor of the one suggested in Kant's On Pedagogy. Doing so will let me subsume the duties against the three vices (drunkenness, gluttony, and lust) under a single, general duty of self-government. Thanks to its rationale, the latter can be extended to other activities intuitively calling for self-government-notably for my purpose, screen exposure.

For Kant, wrongful sexual activities include those 'secundum naturam', 'in accordance with nature' (compatible with procreation, the natural end of the use of sexual organs), like prostitution, adultery, and sexual intercourse between individuals not married to each other. However, in article II he seems to focus only on what he considers wrongful sexual activities 'contra naturam', 'contrary to nature', such as masturbation and homosexuality (Timmons 2013, pp. 237-238; see V-Mo/Collins 27:390-392). ${ }^{18}$ In this article, he runs a problematic teleological argument that

\footnotetext{
16 Timmons's failure to highlight the first rationale leads him to read 'powers' at the end of the last passage back into 'them' at its beginning (2013, p. 235), which is incorrect.

17 The expression is indebted to Timmons (2013, p. 234).

18 Perhaps unsurprisingly, Kant does not consider female masturbation and homosexuality. The case of bestiality introduces further complications. Particularly, the negative causal impact argument by itself cannot easily rule out single tokens of a given act-type, an intuitive desideratum in this case. This problem might be addressed by means of other Kantian resources, but I do not do so here.
} 
fails to meet the burden of explaining why the actions considered are wrong in virtue of being non-procreative (Timmons 2013, pp. 237-241). However, in On Pedagogy Kant mixes teleological claims with remarks on the adverse effects of masturbation on the human being's powers:

Nothing weakens the mind as well as the body of the human being more than the kind of lust which is directed towards oneself, and it is entirely contrary to the nature of the human being ... [The young man must be told that] through it the bodily powers are ruined the most, that it brings on premature old age and that his mind will suffer a great deal in the process, and so forth. (Päd 9:497)

Scientific authorities of Kant's time held masturbation to have harmful effects with regard to the ability to reproduce, but also with regard to one's bodily and mental powers more generally (Kerstein 2008, pp. 212-215). This view was probably quite common in the public opinion of his time too (Timmons 2013, p. 241). This makes room for a Kantian causal argument against practices such as masturbation (Timmons 2013, p. 241), which is important for two reasons.

The first reason is that distinguishing the teleological and the causal argument lets us separate the bad Kant from the good (or at least not-clearly-as-bad) Kant. We can, in other words, decouple Kant's rejection of homosexuality, based on the former, from a more nuanced account of the morality of masturbation based on non-teleological premises. The second reason is that, in so doing, we can bring the duties against lust, drunkenness, and gluttony under the same heading: namely, self-government. ${ }^{19}$ Kant himself reportedly employs the vocabulary of self-government in characterising all three vices in lectures from around 1775 (V-Mo/Collins 27:379). Moreover, a student's notes on his lectures from 1793-94 contain the following moral rationale for self-government: 'constant vigilance [Aufsicht]' of one's intellectual side over one's sensuous side is required 'in regard to all ... inclinations, so that in good or ill fortune [one] knows how to determine [oneself] on principle in all moral situations' (V-MS/Vigilantius 27:663).

\section{On the Empirical Premise of the Negative Causal Impact Argument}

The previous subsections developed a unitary account of Kant's duties against drunkenness, gluttony, and lust. Excessive engagement in the activities they regulate violates a duty of self-government grounded on the negative causal impact of the excess on the human being's mental and bodily powers, which ultimately affects the human being's capacity for morality. This account provides a sufficient basis to address the morality of screen exposure in the same terms. Before doing so, a methodological point is in order. The causal argument leaves it open whether negative effects on the human being's mental and bodily powers result from engaging in certain activities per se, or from engaging in them to a certain degree, or in a

\footnotetext{
19 Assuming, that is, that the main argument against gluttony and drunkenness is the more convincing one concerning 'powers' generally (see the previous subsection). Timmons speaks of 'self-government' and 'self-governance' (2013, p. 224).
} 
specific way or context, and so on. The data to substantiate this empirical premise in the argument is provisionally provided by common sense, and conclusively by scientific research. For example, the folk belief that overdrinking is harmful need not be backed up by sophisticated scientific explanations in order to be adequate in the context of this moral argument; and, for most other activities, including sexual ones such as masturbation, we can think of a limit after which they degenerate into a sort of behavioural addiction, or simply have adverse effects. Scientific research can corroborate or contradict the data of common sense, providing more solid and fine-grained explanations. Arguably, its role is especially important with regard to novel phenomena such as screen exposure. But the general point is that the empirical claims substantiating the negative causal impact argument are not, strictly speaking, the remit of philosophy. So, Timmons's claim that Kant's causal argument against masturbation is weaker than the one against drunkenness and gluttony because the former 'relies on extremely dubious if not outright false claims' (2013, p. 242) based on the science of Kant's time may be defeated by new scientific evidence. ${ }^{20}$

To sum up this section: after interpreting the duties against drunkenness and gluttony as based on the negative causal impact argument, I extended the latter to sexual activities such as masturbation, and suggested that the task of filling in the empirical premise of the argument ultimately be left to scientific research. The general duty of self-government thus introduced provides the framework to address the morality of screen exposure. The case for a duty against screen overexposure takes the negative causal impact argument, and plugs in it the plausible claim (empirically defeasible and susceptible to refinement) that screen overexposure has some adverse effects on the human being's bodily and mental powers. In the next sections, I outline the duty against screen overexposure as an instance of the duty of self-government, and then consider some objections. ${ }^{21}$

\footnotetext{
${ }^{20}$ This is mainly a methodological point, but there is debate on the possible adverse effects of masturbation (typically, in association with screen-based pornography). Most recently, see de Alarcon et al. (2019), Kohut et al. (2019).

${ }^{21}$ A recent paper by Timothy Aylsworth and Clinton Castro (2021) is similar in motivation and objective to the present project, so it will be helpful to clarify the main differences between the two. The first is that Aylsworth and Castro argue for an imperfect duty to oneself to embrace 'digital minimalism' (i.e. to be intentional about one's use of technology; 2021, pp. 1-2), whereas I argue for a perfect duty of self-government owed to the self, of which the duty against screen overexposure is an instance (on the perfect nature of the duty of self-government, see the second objection in the subsection 'Compatibility with Kant's theory' below). The second is that Aylsworth and Castro focus on smartphone use, which they see as 'unique', possibly as a result of their emphasis on the repercussions of unchecked technology use on our cognitive capacities (2021, p. 3; but cf. 2021, n. 14 and n. 21). Instead, my account leaves open the definition of screen exposure, which it inscribes into a general discussion of self-governance, and takes into consideration also the non-cognitive repercussions of screen overexposure. The third difference is that Aylsworth and Castro are less concerned with justifying the Kantian credentials of their account. An example of this is their use of the notion of autonomy - in their view, that which the duty to be digital minimalists protects. For one thing, autonomy is never mentioned in Kant's own discussion of duties to oneself (in fact, it has even been argued that it is absent in the Metaphysics of Morals as a whole; Kleingeld 2018, p. 61). More substantially, Aylsworth and Castro merge a conception of autonomy as 'personal autonomy', (non-Kantian) 'self-governance' (2021, p. 3; on Kantian self-government cf. the end of the previous subsection), with a more Kantian, but still non-moral conception of autonomy, meaning 'rational agency', a 'capacity to set and pursue our chosen ends' (2021, pp. 3-4). Now, although the latter reading is not entirely textually unsupported (on it, cf. Timmermann 2006b), it
} 


\section{The Kantian Duty Against Screen Overexposure}

\section{The Contours of Self-Government}

Determining precisely which screen-based activities (or what degree, context, modality of engagement, etc.) are harmful is not a philosophical task. However, common sense and a growing scientific literature allow the philosopher to legitimately claim that some forms of screen exposure must be harmful, that is, that there is such a thing as screen overexposure. On this basis, some moral guidelines can be modeled, starting from the general idea of self-government. What follows focuses mainly on frequency and degree (or quantity) in drinking, eating, masturbating, and, finally, screen exposure.

Firstly, a Kantian duty of self-government excludes 'habitual brutish excess' (Timmons 2013, p. 235). Habitual excessive drinking straightforwardly leads to the kind of negative effects targeted by the negative causal impact argument. I believe the same can be said for habitual overeating, excessive masturbation, and excessive screen exposure-although it may be hard to draw the exact lines, there must be a threshold beyond which negative effects occur. Secondly, at the other extreme we have mere occasional and non-excessive engagement in these activities. This, on the present account, is permissible not only in the obvious case of eating, but also with regard to occasional and moderate drinking, masturbation, and screen exposure. ${ }^{22}$

Things are more complicated with regard to 'occasional overindulgence' (Timmons 2013, p. 235, emphasis removed). Timmons lists a few reasons why this may be morally problematic, but rightly notes that much depends on the details of risk-assessment (2013, p. 236). One commonsensical reason he puts forward is that occasional overindulgence may turn into habitual overindulgence, and lead to reduced self-government in general; a more specifically Kantian one is that by temporarily impairing certain capacities one may make oneself unable to fulfill positive obligations. Timmons also notes that intuitively morally unobjectionable activities such as thrill rides would be ruled out as impermissible if giving up full control over one's capacities for the sake of pleasure were a sufficient condition in this context (2013, p. 236). Ultimately, fulfilling one's positive obligations involves finding a moral balance, which, arguably, must also take into account the indirect duty to secure one's own happiness (see n. 9 above). More problematic for the permissibility of occasional overindulgence is the possibility that it might lead to violating

\footnotetext{
Footnote 21 (continued)

is unclear whether autonomy so construed can play the role that Aylsworth and Castro assign to it (but cf. their hint at 'the proper exercise of our autonomy', identified with the Kantian good will; 2021, p. 9). My argument refers more directly and less ambiguously to the moral use of our capacities. I should like to thank an anonymous reviewer at Res Publica for drawing my attention to Aylsworth and Castro's paper.

22 I use 'drinking' for 'drinking alcoholic beverages' (although the argument extends to coffee, sugary beverages, etc.). With regard to quality and quantity, Kant reportedly says: 'Drinking to excess does not refer to quantity (nobody ever gets a passion for drinking large amounts of water), but to the refinement and quality of the beverage; but in eating, a man can be led into excess even by bad food' (V-Mo/Collins $27: 380)$.
} 
strict duties. One of Kant's examples in his discussion of imputation is that wrongful actions performed while drunk cannot be imputed to one as free deeds, but one is still accountable for the choice of getting drunk (V-Mo/Collins 27:288; 27:291; V-MS/Vigilantius 27:559; 27:568).

Taking cue from Timmons's reference to risk-taking, the following case may serve to test our intuitions about occasional overindulgence, particularly those of worried Kantians: ${ }^{23}$

Kantian Trip: After a week spent working, volunteering, and practicing the piano, Sanga is having a relaxing day with her friends of the Kant Reading Group. Among the many planned social activities, some of the friends, including Sanga, are going to take a hallucinogenic drug. This drug, legal by the law of the land, is expected to impair for some time the cognitive and deliberative capacities of those taking it. The group has chosen it specifically because of the short duration of its effects (say, around half an hour). The group has taken every reasonable precaution to avoid short- and long-term harm to those taking the drug, the others in the group, and other people; and to prevent violations of strict duties. After the trip is over, those who took the drug will share their experience with the whole group, and then everyone will go back to reading the second Critique under a starry sky.

Sanga regularly fulfills her positive duties. The day involves social activities, and the hallucinogenic drug experience too, while per se solitary, is not undertaken in an anti-social spirit. ${ }^{24}$ Risk of harm to the drug users themselves, to the other friends, or to other people has been reasonably minimized. Likewise, no violation of strict duties is likely to occur. Given all this, it looks to me that the burden is on those who would claim that Sanga's taking the hallucinogenic drug is impermissible. More generally, restrictive Kantian arguments against occasional overindulgence are likely to be either question-begging in simply stating that occasional overindulgence is incompatible with one's dignity, or questionable insofar as they conceive of certain acts as inherently self-degrading on problematic teleological grounds. ${ }^{25}$

Insofar as the moral considerations at issue in the present paper only are concerned, I believe, this rough model largely tracks commonsensical considerations. The upshots concerning screen exposure (which, recall, I purposefully defined in broad terms) are that (i) habitual screen overexposure is impermissible and (ii)

\footnotetext{
${ }^{23}$ Kantian Trip is about a hallucinogenic drug, but a similar case could be constructed about overdrinking.

24 This pre-empts an objection from anti-sociality. While Kant deems gluttony worse than drunkenness (as the former 'does not even arouse imagination to an active play of representations'; TL 6:427), he reportedly condemns solitary drinking and drunkenness (putting them at the same level as gluttony; VMo/Collins 27:381; V-MS/Vigilantius 27:633), and explicitly deplores 'all silent intoxication', namely 'intoxication that does not enliven sociability and the reciprocal communication of thought' (ApH 7:170-172; see also TL 6:428).

25 This is different from the argument that certain actions are inherently self-degrading insofar as they express something defective about one's character (Timmons 2013, p. 225 n. 7). There seems to be nothing morally objectionable in, as it were, responsible overindulgence.
} 
moderate or occasional screen exposure is permissible. It is harder to give a single verdict concerning (iii) occasional screen overexposure (say, binge video-gaming on occasion), but this is the same for other activities calling for self-government. A lot will depend on the specific activity and other factors such as duration, quality of engagement (e.g. immersiveness), context, and aim of the activity. However, so long as the negative causal impact argument only is concerned, I believe that occasional screen overexposure (and occasional overindulgence generally) should not be ruled out as impermissible.

The duty against screen overexposure provides a Kantian basis for more fine-grained accounts of the morality of engagement with specific screen-based technologies. The present account focuses on the morality of screen exposure solely from the perspective of a duty to oneself, namely the duty of self-government. As such, it aims neither to discuss the considerations that would speak in favor of screen exposure in specific circumstances, nor the other ways in which screen exposure or overexposure might be morally problematic. However, considering some objections will allow me to flesh out my account in a bit more detail.

\section{Objections}

\section{Extensional Adequacy}

A first set of objections concerns the extensional adequacy of the duty against screen overexposure. The first is that on the model outlined in the last subsection the duty prohibits, for example, academics from working for long stretches of time on laptops, or physicians from using medical equipment with screens. The objection may be accommodated by restricting the scope of the duty to screen use aimed at pleasure or happiness only (compare Timmons's thrill rides example in the previous subsection). This straightforwardly excludes eating and hydrating for sustenance, but also activities not immediately aimed at pleasure or happiness. Producing knowledge and providing medical care, while involving some element of gratification, also constitute the fulfillment of moral obligations, and so the examples given above are excluded from the discussion.

A second objection focuses on screen-based activities that increase one's rational capacities-for example, reading on an electronic reader. This can be addressed by noting that merely looking at a screen does not necessarily count as screen exposure. Recall, the family resemblance definition of screen exposure introduced at the beginning of the paper was already meant to capture screen-based activities which raise worries of the relevant kind. In this sense, it was not neutral to begin with. In the electronic reader example, once the worries are detached from the specific technology, the question becomes whether one can read so much so as to violate a duty of self-government. But, especially on a Kantian picture, improving one's rational capacities seems to be permissible almost by definition.

A third objection is that the negative causal impact argument cannot account for cases where the pathological engagement in a certain activity or the use of certain substances coexists well with one's capacities. An example is the variety of 
'high-functioning' -isms (e.g. alcoholism). A commonsensical, empirical reply may be that the abuse eventually catches up. More importantly perhaps, what matters ultimately is not one's mental or bodily powers in themselves, but rather their moral use. The negative causal impact argument does not protect human mental (or physical) capacities because they have value in isolation: it protects them in view of their being put to good use. This cannot be limited to 'functioning' well in a professional or social context, but is a more encompassing, and, as it were, holistic notion, captured by Kant's reference to perfection (particularly, moral perfection). ${ }^{26}$ This somewhat indirect response also serves to address a related objection which focuses on the use of substances aimed at improving one's rational capacities (cognitive enhancers). This objection goes further than mere coexistence with said capacities (granted, for the sake of argument, in cases of 'high-functioning'). Rather, it mirrors the second one above, concerning screen-based activities that increase them. Together, the two raise the interesting question whether Kant's theory should set limits on the improvement of rational capacities, which I cannot take up here. ${ }^{27}$

\section{Compatibility with Kant's Theory}

Another set of objections concerns the compatibility of my account with Kant's system of duties. The first is that my duty of self-government alters Kant's account of the duty to oneself as an animal being (on what follows, see the section 'Kantian resources' above). I grant this point so far as it focuses on his schematic and teleology-driven derivation of the three articles on the basis of the human being's alleged animal impulses. However, my account is compatible with Kant's general classification of duties to oneself. The duties falling under self-government are still negative. Moreover, my account is also compatible with the different classification of duties to oneself as animal being specifically, given at the beginning of the corresponding section of the Doctrine of Virtue, where Kant distinguishes murdering and maiming oneself from formal self-mutilation. These classifications are equally plausible, particularly in virtue of what the latter entails about the article on lust. There are overwhelming independent reasons to endorse a non-teleological and more empirically-informed account of the morality of sexual activities. By doing so, to summarize, our classification comes to include a duty against murdering and maiming oneself, and a general duty of self-government, which regulates activities potentially harmful to human capacities.

The second objection is that the duty of self-government looks too much like an imperfect duty, in conflict with the title of the chapter on which it is based. This is not the case. Its characterization as a duty of omission largely depends on the description of what it prohibits. It is also true that it does look as an imperfect duty insofar as it regards maxims as policies involving a certain flexibility (what Kant

\footnotetext{
${ }^{26}$ However, on the present account, screen exposure is morally problematic if it interferes with one's profession, or causes social withdrawal.

27 See Bauer (2018). A similar discussion could be had about pathological engagement in activities normally aimed at enhancing one's physical powers.
} 
calls 'latitude'; TL 6:390) over time. Still, the duty exercises a negative limitation: it does not prescribe the adoption of ends. Self-government falls under what Kant calls 'moral health', and so it is a mere precondition for the pursuit of one's perfection and of the happiness of others (see the subsection 'A duty of self-government' above).$^{28}$ Admittedly, much potentially hinges also on the plausibility of my case for the permissibility of occasional overindulgence (see the discussion of Kantian Trip above), since the latter arguably is a good candidate for a one-off action that one would expect a perfect duty to forbid. ${ }^{29}$

\section{Why a Duty Against Screen Overexposure? and Why a Kantian Duty of Self- Governance?}

Finally, two objections cast doubt in different ways on the project's motivation and significance. ${ }^{30}$ The first is that screen overexposure is not sufficiently distinct from other activities with a similar negative causal impact to justify the introduction of a specific duty against it. Unless there is something distinctive about screen overexposure, the objection goes, introducing a duty against it is a philosophically uninteresting rehashing of Kant's argumentative strategy. If we can apply the latter with unsurprising results to many activities to which Kant himself either did not or could not apply it, what is the added value of focusing on screen exposure?

While I do think that there is something special about screen exposure, I doubt that a single feature of it could justify a duty specifically against screen overexposure. None of the morally salient features of screen exposure strikes me as unique

\footnotetext{
28 In his discussion of drunkenness and gluttony, Kant writes: 'Here the reason for considering this kind of excess a vice is not the harm ... that a human being brings on himself by it; for then the principle by which it is to be counteracted would be one of [happiness] and such a principle can establish only a rule of prudence, never a duty - at least not a direct duty' (TL 6:427, emphasis added). This seems to imply that Kant intends to establish a direct duty. Another objection concerning the Kantian credentials of my account, then, is that the duty of self-government, instead, looks like an indirect duty. The latter consists in, roughly, a permissible course of action aimed at the preservation of one's well-being, which can be indirectly commanded insofar as preserving some level of well-being is a safeguard against immorality (see n. 9 above). Firstly, regardless of Kant's own intentions, the quotation just given does not exclude the possibility of understanding the duty (also) as an indirect duty. Secondly, Kant's pointing to a more robustly moral version of the duty may be due to the teleological nature of the argument. Thirdly, unlike Kant's own examples of indirect duties, the duty of self-government remains negative. Finally, Kantians have questioned the moral status of indirect duties, which at the very least does not seem to constitute a category of duties in their own right, alongside, for example, perfect and imperfect duties (Timmermann 2007, p. 36). The following options are available to Kantians: (i) give up duties to oneself as an animal being entirely, and bring the concerns they capture entirely under the sphere of prudence; (ii) accept a teleological reading of such duties to read them unambiguously as direct duties; (iii) give up the category of indirect duties altogether; (iv) interpret duties to oneself as an animal being as (also) indirect duties. I listed these options from least to most preferable, and for the time being I endorse (iv).

29 Which it still need not forbid under all circumstances (see Timmons 2013, p. 223). The modalities of permissible indulgence will be a function of many factors, including absence of conflict with strict duties and harmonization with wide duties. Ultimately, like compliance with all duties, compliance with the duty of self-government requires practical judgment.

30 I would like to thank an anonymous reviewer at Res Publica for raising both.
} 
to it. ${ }^{31}$ Just to make some examples: like alcohol consumption, screen exposure is widely socially accepted; like the use of some psychoactive drugs, its negative effects can be subtle and may take a long time to manifest themselves fully; like sexual activity, it is neither necessarily social nor necessarily asocial. However, I believe it is the particular combination of features characterizing screen exposure that makes screen overexposure a problem worth considering in its own right, beyond the general duty of self-government.

This response is based on a hunch. But this is consistent with the reason why I did not try to provide an exhaustive definition of screen exposure. This phenomenon is still unfolding before our eyes, and we do not yet fully grasp its ramifications, its causal impact on us, and its moral significance. I think all are likely to be huge (no technological dystopianism intended). This does not exclude that, in the future, screen overexposure (or some specific instance of it) will be seen as a textbook example of lack of self-government. For the time being, however, it is important to put the spotlight on it.

Furthermore, a Kantian duty against screen overexposure plays an important role for Kantian moral philosophy. If duties to oneself are part of morality, Kantians arguably should 'cast aside those of Kant's examples that command little or no assent today, and look for new paradigm cases of duties to the self' (Timmermann 2006a, p. 521). In this respect, a duty against screen overexposure may succeed where a general duty of self-government may not. From a Kantian perspective, then, the former makes even more sense.

This brings me to the second objection, namely that more justification is needed to take a Kantian approach to the morality of screen exposure, and self-government more generally: are there independently plausible reasons to do so?

Firstly, most of us spend too much time in front of screens while perceiving that there is something wrong with it. I think that the intuition that this wrongness cannot be reduced to the impact of screen overexposure on one's well-being or to its indirect effects on others is not theory-laden. Kant's theory, particularly his duties to the self, is highly suitable to account for this intuition.

This, secondly, might even lead non-Kantians to wonder whether Kant is right in seeing the self/others distinction as to some extent a moral red herring. The relevant distinction, for Kant, is between reason and inclinations: morality is not about 'the supremacy of (allegedly good) other-regarding reasons over (supposedly bad) self-regarding ones, but rather the priority of rational, universal, timeless principles of action over the questionable claims of the non-rational elements of human nature' (Timmermann 2006a, p. 525).

Finally, and relatedly, approaching issues of self-government via Kantian duties to oneself can be appealing on broadly egalitarian grounds. Within a Kantian

\footnotetext{
31 A possible exception might be the pervasiveness of screen exposure (there seems to be no way to live in an information society without engaging in it), but even this property is arguably not unique to it (think about, for example, food consumption). Although identifying a single feature of screen exposure that distinguishes it from other activities intuitively requiring some degree of self-government would strengthen my response to the objection under consideration, the response in the main text is, I believe, sufficient.
} 
conception of morality, one must respect humanity in others and in oneself (see the subsection 'Duties to Oneself and Kantian Duties to Oneself' above). Reason forces agents to recognize their own dignity, which is ultimately based on their capacity for moral action and which exacts respect from others and from oneself. From this perspective, Kantian duties to oneself express a requirement of impartiality in not excluding oneself from the scope of morality (Denis 1997, p. 343).

\title{
Conclusion
}

This paper offered a technologically updated plea for the traditional idea of moderation. It is to be expected that the definition and the morality of screen exposure will be explored in further detail in the future. It is also likely that more fine-grained and differentiated assessments of the morality of engagement with specific screen-based technologies will be put forward. By subsuming the morality of screen exposure under the more general heading of self-government, this paper provided a Kantian framework for this further research.

Acknowledgements For comments on earlier drafts of the paper, I am grateful to Lewis Ross, Martin Sticker, Jens Timmermann, and the anonymous reviewers at Res Publica and two other journals. For helpful feedback, I would like to thank Nina Dmitrieva, Claire Field, and Janis Schaab. A special thanks to Heloise McKeown for her unwavering support. This research was supported by the Russian Academic Excellence Project at the Immanuel Kant Baltic Federal University.

Open Access This article is licensed under a Creative Commons Attribution 4.0 International License, which permits use, sharing, adaptation, distribution and reproduction in any medium or format, as long as you give appropriate credit to the original author(s) and the source, provide a link to the Creative Commons licence, and indicate if changes were made. The images or other third party material in this article are included in the article's Creative Commons licence, unless indicated otherwise in a credit line to the material. If material is not included in the article's Creative Commons licence and your intended use is not permitted by statutory regulation or exceeds the permitted use, you will need to obtain permission directly from the copyright holder. To view a copy of this licence, visit http://creativecommons.org/licen ses/by/4.0/.

\section{References}

\author{
When citing Kant I refer to volume and page in the Akademie-Ausgabe (Kant \\ 1900—), from which I also take the quotes in German. Quotations are from the \\ Cambridge Edition of the Works of Immanuel Kant (eds P. Guyer, A. Wood). I use \\ the following abbreviations: $\mathrm{ApH}=$ Anthropology from a Pragmatic Point of View; \\ GMS = Groundwork of the Metaphysics of Morals; KpV = Critique of Practical
}




\section{Reason; MS = Metaphysics of Morals; Päd = On Pedagogy; TL $=$ Metaphysical First Principles of the Doctrine of Virtue; V-Mo/Collins = Moral philosophy: Collins's Lecture Notes; V-MS/Vigilantius = Kant on the Metaphysics of Morals: Vigilantius's Lecture Notes.}

Alpinar-Şencan, Zümrüt. 2016. Reconsidering Kantian arguments against organ selling. Medicine, Health Care and Philosophy 19 (1): 21-31.

Andreassen, Cecilie S., Torbjørn Torsheim, Geir S. Brunborg, and Ståle. Pallesen. 2012. Development of a facebook addiction scale. Psychological Reports 110 (2): 501-517.

Atwell, John E. 1986. Ends and principles in Kant's moral thought. The Hague: Martinus Nijhoff.

Aylsworth, Timothy, Clinton Castro. 2021. Is there a duty to be a digital minimalist? Journal of Applied Philosophy 1-12. Advance online publication. https://doi.org/10.1111/japp.12498>

Bacin, Stefano. 2013. The perfect duty to oneself merely as a moral being (TL 6:428-437). In Kant's "Tugendlehre": a comprehensive commentary, ed. Andreas Trampota, Oliver Sensen, and Jens Timmermann, 245-268. Berlin, Boston: Walter de Gruyter.

Baier, Kurt. 1958. The moral point of view: a rational basis of ethics. Ithaca, New York: Cornell University Press.

Bauer, Katharina. 2018. Cognitive self-enhancement as a duty to oneself: A Kantian perspective. The Southern Journal of Philosophy 56 (1): 36-58.

Baxley, Anne M. 2010. Kant's theory of virtue: The value of autocracy. Cambridge: Cambridge University Press.

Betzler, Monika, ed. 2008. Kant's ethics of virtue. Berlin, Boston: Walter de Gruyter.

Byrd, Sharon B., and Joachim Hruschka. 2010. Kant's 'Doctrine of Right': A commentary. Cambridge: Cambridge University Press.

Cholbi, Michael. 2015a. On Marcus Singer's “On duties to oneself.” Ethics 125 (3): 851-853.

Cholbi, Michael. 2015b. Kant on euthanasia and the duty to die: Clearing the air. Journal of Medical Ethics 41 (8): 607-610.

Cohen, Alix A. 2008a. The ultimate Kantian experience: Kant on dinner parties. History of Philosophy Quarterly 25 (4): 315-336.

Cohen, Alix A. 2008b. Kant's answer to the question "what is man?" and its implications for anthropology. Studies in History and Philosophy of Science Part A 39 (4): 506-514.

Cohen, Alix A. 2006. Kant on epigenesis, monogenesis and human nature: The biological premises of anthropology. Studies in History and Philosophy of Science Part C: Studies in History and Philosophy of Biological and Biomedical Sciences 37 (4): 675-693.

Darwall, Stephen L. 2013. Bipolar obligation. In Morality, authority and law: Essays in second-personal ethics I, Authority Morality, 20-39. Oxford: Oxford University Press.

Darwall, Stephen L. 2006. The second-person standpoint: Morality, respect, and accountability. Cambridge: Harvard University Press.

Denis, Lara, ed. 2010. Kant's "Metaphysics of Morals": A critical guide. Cambridge: Cambridge University Press.

Denis, Lara. 1997. Kant's ethics and duties to oneself. Pacific Philosophical Quarterly 78 (4): 321-348.

de Alarcón, Rubén, Javier I. de la Iglesia, Nerea M. Casado, and Angel L. Montejo. 2019. Online porn addiction: What we know and what we don't a systematic review. Journal of Clinical Medicine 8 (1): 91 .

Diagnostic and statistical manual of mental disorders fifth edition DSM- ${ }^{\mathrm{TM}}$. Section III: Conditions for further study. American Psychiatric Association.

Dunckley, Victoria L. 2017. Electronic screen syndrome: Prevention and treatment. In: Internet additcion in children and adolescents: Risk, eds. Kimberly S. Young, Christian. N. de Abreu, 213242. New York: Springer Publishing Company

Formosa, Paul. 2011. A life without affects and passions: Kant on the duty of apathy. Parrhesia 13: 96-111.

Frierson, Patrick R. 2013. What is the human being? Abingdon and New York: Routledge.

Gregor, Mary J. 1963. Laws of freedom: A study of Kant's method of applying the categorical imperative in the Metaphysik der Sitten. Oxford: Blackwell. 
Hill, Thomas E. 2010. Kant's Tugendlehre as normative ethics. In Kant's “Metaphysics of morals" sin: A critical guide, ed. Lara Denis, 234-255. Cambridge: Cambridge University Press.

Hill, Thomas E. 1973. Servility and self-respect. The Monist 57 (1): 87-104.

Kading, Daniel. 1960. Are there really 'no duties to oneself'. Ethics 70: 155-157.

Kant I. 1900- Kants gesammelte Schriften, ed. Royal Prussian Academy of Sciences, Walter de Gruyter, Berlin.

Kardaras, Nicholas. 2016. Glow kids: How screen addiction is hijacking our kids-and how to break the trance. New York: St. Martin's Press.

Kerstein, Samuel J. 2008. Treating oneself merely as a means. In Kant's ethics of virtue, ed. Monika Betzler, 197-214. Berlin, Boston: Walter de Gruyter.

Kleingeld, Pauline. 2018. The principle of autonomy in Kant's moral theory: Its rise and fall. In Kant on persons and agency, ed. Erik Watkins, 61-79. Cambridge: Cambridge University Press.

Knight, Frank H. 1961. I, me, my self, and my duties. Ethics 71: 209-223.

Ko, Chih Hung, Ju.Y. Yen, Cheng F. Yen, Cheng S. Chen, and Cheng C. Chen. 2012. The association between internet addiction and psychiatric disorder: A review of the literature. European Psychiatry 27 (1): 1-8.

Kohut, Taylor, Rhonda N. Balzarini, William A. Fisher, Joshua B. Grubbs, Lorne Campbell, and Nicole Prause. 2019. Surveying pornography use: A shaky science resting on poor measurement foundations. The Journal of Sex Research 10: 1-21.

Kuss, Daria J., Mark D. Griffiths, Karila Laurent, and Joël. Billieux. 2014. Internet addiction: A systematic review of epidemiological research for the last decade. Current Pharmaceutical Design 25: 4026-4052.

Kwon, Min, Joon Y. Lee, Wang Y. Won, Jae W. Park, Jung A. Min, Changtae Hahn, Gu. Xinyu, Ji. H. Choi, and Dai J. Kim. 2013. Development and validation of a smartphone addiction scale (SAS). PLOS ONE 8 (2): e56936.

Louden, Robert B. 2011. Kant's human being: Essays on his theory of human nature. Oxford, New York: Oxford University Press.

Mothersill, Mary. 1960. Professor Wick on duties to oneself. Ethics 71: 205-208.

Muñoz, Daniel. 2020. The paradox of duties to oneself. Australasian Journal of Philosophy 98 (4): 691-702.

Petry, Nancy M., Florian Rehbein, Chih H. Ko, and Charles P. O’Brien. 2015. Internet gaming disorder in the DSM-5. Current Psychiatry Reports. 17 (9): 72.

Pontes, Halley M., Bruno Schivinski, Cornelia Sindermann, Mei Li, Benjamin Becker, Min Zhou, and Christian Montag. 2019. Measurement and conceptualization of gaming disorder according to the world health organization framework: The development of the gaming disorder test. International Journal of Mental Health and Addiction. https://doi.org/10.1007/s11469-019-00088-z.

Potenza, Marc N. 2014. Non-substance addictive behaviors in the context of DSM-5. Addictive Behaviors 39 (1): 1-2.

Schaab, Janis D. 2021a. Kant and the second person. Journal of the American Philosophical Association. https://doi.org/10.1017/apa.2020.49.

Schaab, Janis D. 2021b. On the supposed incoherence of obligations to oneself. Australasian Journal of Philosophy 99 (1): 175-189.

Schumski, Irina. 2017. Make no exceptions for yourself:-A Kantian response to the particularist challenge. PhD dissertation, University of Warwick. http://wrap.warwick.ac.uk/102839/

Schüssler, Rudolf. 2012. Kant und die Kasuistik: Fragen zur Tugendlehre. Kant-Studien 103 (1): 70-95.

Singer, Marcus G. 1963. Duties and duties to oneself. Ethics 73 (2): 133-142.

Singer, Marcus G. 1959. On duties to oneself. Ethics 69 (3): 202-205.

Timmermann, Jens. 2013. Duties to oneself as such. In Kant's "Tugendlehre”: A comprehensive commentary, ed. Andreas Trampota, Oliver Sensen, and Jens Timmermann, 207-220. Berlin, Boston: Walter de Gruyter.

Timmermann, Jens. 2007. Kant's “Groundwork of the metaphysics of morals”: A commentary. Cambridge: Cambridge University Press.

Timmermann, Jens. 2006a. Kantian duties to the self, explained and defended. Philosophy 81 (3): $505-530$.

Timmermann, Jens. 2006b. Value without regress: Kant's 'formula of humanity' revisited. European Journal of Philosophy 14 (1): 69-93. 
Timmons, Mark. 2013. The perfect duty to oneself as an animal being (TL 6:421-428). In Kant's "Tugendlehre": A comprehensive commentary, ed. Andreas Trampota, Oliver Sensen, and Jens Timmermann, 221-244. Berlin, Boston: Walter de Gruyter.

Timmons, Mark, ed. 2002. Kant's "Metaphysics of morals": Interpretative essays. Oxford, New York: Oxford University Press.

Trampota, Andreas, Oliver Sensen, and Jens Timmermann, eds. 2013. Kant's "Tugendlehre": A comprehensive commentary. Berlin, Boston: Walter de Gruyter.

Twenge, Jean M., Gabrielle N. Martin, and W. Keith Campbell. 2018. Decreases in psychological well-being among american adolescents after 2012 and links to screen time during the rise of smartphone technology. Emotion 18 (6): 765-780.

Varden, Helga. 2020. Sex, love, and gender: A Kantian theory. Oxford, New York: Oxford University Press.

Wick, Warner. 1961. Still more about duties to oneself. Ethics 71: 213-217.

Wick, Warner. 1960. More about duties to oneself. Ethics 70: 158-163.

Williams, Bernard. 1985. Ethics and the limits of philosophy. Cambridge, Massachusetts: Harvard University Press.

Wood, Allen W. 2007. Kantian ethics. Cambridge: Cambridge University Press.

Wood, Allen W. 2002. The final form of Kant's practical philosophy. In Kant's "Metaphysics of morals": Interpretative, ed. Mark Timmons, 1-22. Oxford, New York: Oxford University Press.

World Health Organization. 2018. International classification of diseases for mortality and morbidity statistics (11th revision). https://icd.who.int/browse11/1-m/en.

Yildiz, Mehmet A. 2017. Emotion regulation strategies as predictors of internet addiction and smartphone addiction in adolescents. Journal of Educational Sciences \& Psychology 7 (1): 66-78.

Young, Kimberly S. 2016. Internet addiction test (IAT). Wood Dale: Stoelting.

Publisher's Note Springer Nature remains neutral with regard to jurisdictional claims in published maps and institutional affiliations. 